\section{Pengalaman Spiritual Survivor \\ Cervical Cancer : Studi Fenomenologi}

\author{
Fenomenologi
}

\begin{abstract}
NURSCOPE
Jurnal Keperawatan dan Pemikiran IImiah

Distinarista, D (2018). Pengalaman spiritual

survivor cervical cancer : studi fenomenologi .

Nurscope.Jurnal Keperawatan Pemikiranllmiah.
\end{abstract}

4 (5). 30-40

\author{
Hernandia Distinarista ${ }^{1}$ \\ ${ }^{1}$ Fakultas Ilmu Keperawatan, Universitas Islam Sultan Agung Semarang.
}

\begin{abstract}
Abstrak
Spiritualitas sangat dibutuhkan dalam menangani penderita kanker serviks. Penelitian membuktikan bahwa penderita kanker serviks yang memiliki tingkat spiritual rendah cenderung lebih depresifdaripada penderita kanker serviks dengan tingkat spiritual baik. Penelitian ini dirancang untuk mengeksplorasi pengalaman spiritualsurvivor cancer pada pasien kanker serviks.Penelitian ini menggunakan metode fenomenologi hermeneutik, melibatkan lima partisipan di wilayah Demak, Jepara dan Kendal. Pengambilan data dilakukan dengan wawancara semi terstruktur yang selanjutnya dilakukan transkipsi data. Analisa data menggunakan content analysis. Pada penelitian ini kelima partisipan survivor cancer pada pasien kanker serviks menunjukkan bahwa spiritual memberian kekuatan dan motivasi pada partisipan dalam menjalani pengobatan hingga dinyataan sembuh.
\end{abstract}

Kata Kunci: Cervical cancer, Pengalaman spiritual , Survivor

\title{
Spiritual Experience Among Cervical Cancer Survivors: A Phenomenology Study
}

\begin{abstract}
Spirituality is needed in dealing with cervical cancer patients. Researches show that cervical cancer patients who have low spiritual level tend to be more depressive compared to those with good spiritual level. This study aimed to explore the spiritual experience of survivor among cervical cancer patients. The study used a hermeneutic phenomenology method, involving five participants in Demak, Jepara and Kendal areas. Data retrieval was collected by semi structured interview followed by data transciption. Data analysis used content analysis. The finding showed that the spiritual gave strength and motivation to those participants since they were having treatment until healed.
\end{abstract}

Keywords: Cervical cancer, spiritual experience, survivor

Corresponding Author:

Hernandia Distinarista ${ }^{1}$, Fakultas IImu Keperawatan Universitas Islam Sultan Agung Semarang JI.Raya Kaligawe Km.4 PO.BOX 1054 Semarang 50112

hernandia.distinarista@gmail.com 


\section{PENDAHULUAN}

Penyakit kronis merupakan penyakit yang berkepanjangan, tidak mudah disembuhkan dan jarang dapat sembuh sempurna. Penyakit kronis dapat menyebabkan masalah medis, sosial dan psikologis (Natuveli, 2005; Canbaz, 2002). Penyakit kronis mengakibatkan pasien merasa sakit dan lemah dalam jangka waktu yang lama salah satunya adalah penyakit kanker. Penyakit kanker merupakan penyakit dengan jumlah kematian tertinggi kedua setelah penyakit jantung di dunia (WHO, 2015).

Secara nasional prevalensi penyakit kanker tahun 2016 terdapat 17,8 juta jiwa (Subagja, 2017). Pasien dengan kanker serviks di Jawa Tengah pada tahun 2013 sebanyak 19.734 pasien (Pusat Data dan Informasi, 2015). Di Kota Semarang pada tahun 2015 terdapat 310 orang, pada tahun 2016 meningkat menjadi 357 orang. Di RSUP dr Kariadi Semarang pada tahun 2014 terdapat 141 pasien dengan kanker serviks dan meningkat menjadi 276 pasien pada tahun 2015 (DKK Semarang, 2015).

Kanker berdampak terhadap seluruh aspek kehidupan penderita baik fisik, psikologis maupun spiritual. Pada penelitian persepsi dan harapan perempuan dengan kanker serviks didapatkan lima tema utama yaitu: pengalaman perempuan pada awal diagnosis kanker serviks, pengalaman terhadap kebutuhan spiritual, dukungan spiritual yang diberikan perawat, harapan terhadap penyedia sarana ibadah, dan harapan terhadap asuhan keperawatan spiritual (Nuraeni, 2010).

Penelitian kebutuhan spiritual pada pasien kanker mendapatkan hasil bahwa semua dimensi kebutuhan spiritual sangat dibutuhkan oleh pasien kanker. Kebutuhan religi merupakan kebutuhan yang paling banyak dipilih dan dirasakan oleh pasien paling dibutuhkan (Nuraeni; Nurhidayah, Hidayati, 2015).

Angka ketahanan hidup pada pasien kanker serviks masih rendah. Pada pasien yang dapat survive belum ada data yang mendalam bagaimana pengalaman spiritual survivor cervical cancersehingga butuh dieksplorasi.. Dengan hasil penelitian ini diharapkan pasien kanker yang sedang menjalani pengobatan mendapatkan hasil riset yang mendukung, agar dapat menjalani pengobatan berkualitas dengan maksimal dan dapat menjalani kehidupan dalam jangka panjang.

\section{METODE}

Desain penelitian ini adalah penelitian kualitatif dengan pendekatan fenomenologi hermeneutik yang merupakan pendekatan yang mengasumsikan temuan-temuan riset tidak murni hasi Ideskripsi tetapi lebih merupakan interpretasi peneliti (Afiyanti, 2014). Proses metodologi deskriptif fenomenologi meliputi empat langkah yaitu bracketing, intuiting, analyzing, dan describing (Polit, D.F., \& Hungler, 2012). Populasi dalam penelitian ini adalah cervical cancer survivor di Provinsi Jawa Tengah yang telah dinyatakan remisi oleh dokter penanggung jawab pasien di RSUP Dr Kariadi Semarang, dan menjalani kontrol pap smear 1-2 kali dalam satu tahun.

Teknik pengambilan sampel yang digunakan adalah purposive sampling(Afiyanti, 2014). Adapun kriteria inklusi partisipan diantaranya : 1) perempuan usia $\geq 20$ tahun; 2) Minimal telah atau belum menikah; 3) Minimal 5 tahun setelah terdiagnosa kanker; 4) Tidak mengalami gangguan kognitif; 
5) telah dinyatakan sembuh; 6) Tidak mengalami komplikasi, 7) Bersedia dan setuju untuk menjadi partisipan dalam penelitian. Peneliti mengurus ijin studi pendahuluan ke RSUP dr. Kariadi Semarang, peneliti telah mendapatkan surat keterangan Ethical Clerance No. 472/EC/FKRSDK/VII/2017 dari Komisi Etik Penelitian Kesehatan (KEPK) Fakultas Kedokteran Universitas Diponegoro Dan RSUP dr Kariadi Semarang, dan mengurus surat ijin penelitian ke Kesbangpol Provinsi Jawa Tengah.

Peneliti mengidentifikasi calon partisipan yang berada di poli klinik onkologi dengan bantuan dari tim kesehatan Ruang Onkologi. Setelah calon partisipan teridentifikasi dengan memperhatikan criteria inklusi, peneliti melakukan pendekatan kepada calon partisipan untuk membina hubungan saling percaya. Kemudian peneliti menjelaskan kontrak waktu dengan partisipan mengenai penelitian yang akan berlangsung. Jika calon partisipan setuju, maka peneliti menjelaskan tujuan, manfaat serta prosedur penelitian yang dilakukan.

Peneliti meminta calon partisipan untuk mengisi informed consent sebagai bukti bahwa calon partisipan bersedia dengan sukarela dan tanpa ada paksaan dari pihak manapun untuk berpartisipasi dalam penelitian ini. Pengambilan data dilakukan dengan wawancara semi terstruktur serta menuliskan hasil wawancara dan mendokumentasikan ke dalam bentuk transkip. Pewawancara adalah peneliti sendiri, pekerjaan sebagai pengajar, jenis kelamin perempuan, memiliki sedikit pengalaman merawat pasien di bangsal onkologi dan telah melakukan survey terhadap beberapa cancer survivor.

\section{Analisa Data}

Hasil wawancara dianalisa menggunakan content analysis berdasarkan Elo dan Kyngäs (2008). Content analysis terdiri dari transcribing (membuat transkrip percakapan perawat dan pasien), menentukan meaning unit untuk mencari hubungan antar kata, kalimat atau paragraf dan terakhir, melakukan abstraksi data hingga membentuk beberapa tema.

\section{HASIL}

Dalam penelitian ini didapatkan5 cervical cancer survivor di Provinsi Jawa Tengah (1 partisipan bertempat tinggal di Demak, 2 partisipan bertempat tinggal di Jepara, dan 2 partisipan bertempat tinggal di Kendal). Peneliti menggali apa yang partisipan rasakan, alami, lakukan terkait pengalaman selama terdiagnosa kanker serviks.

P1 telah menjalani pengobatan kanker dengan kemoterapi, radiasi, loading, dan mengkonsumsi herbal. Saat ini P1 menunggu jadwal control dan pap smear yang dijadwalkan pada bulan September. P1 berusia 49 tahun, mempunyai dua orang putri. Riwayat di diagnose kanker stadium kanker 3B, remisi pada tahun 2012, pendidikan terakhir SD, dan menikah sejak usia 16 tahun dan dapat berkomunikasi dengan baik.

P2 berusia 55 tahun, memiliki pengalaman dan menjalani pengobatan kanker yaitu radiasi, loading, dan kemoterapi. Saat ini P2 menunggu jadwal control dan pap smear. P2 menikah usia 14 tahun dan memiliki enam putra putri. P2 di diagnose kanker stadium 3B , dinyatakan remisi pada tahun 2008 pendidikan terakhir SD dan dapat berkomunikasi dengan baik. 
P3 berusia 67 tahun, P3 tampak sehat, di diagnose kanker serviks stadium 3B, dinyatakan remisi pada tahun 2008 pengobatan kanker yang telah beliau jalani yaitu radiasi, bistral dan loading. Saat ini P3 menunggu jadwal control dan pap smear pada bulan Desember. Pendidikan terakhir SD, menikah usia 11 tahun dan memiliki 5 putra dan putri.

P4 berusia 63 tahun, Riwayat pernikahan menikah usia 14 tahun, memiliki 6 orang putra dan putri. Beliau didiagnosa kanker serviks stadium II B, dinyatakan remisi tahun 2012. Pengobatan kanker yang telah dijalaninya adalah radiasi, loading dan kemoterapi. Saat ini pasien menunggu jadwal control dan pap smear.

P5 berusia 62 tahun, Menikah usia 22 tahun dan memiliki 4 orang putra dan putri. Beliau di diagnose kanker serviks stadium 3B, remisi pada tahun 2004 pengobatan kanker yang pernah beliau jalani adalah radiasi, loading dan kemoterapi. Pendidikan terakhir SD dan dapat berkomunikasi dengan baik. Saat ini beliau menunggu jadwal control dan pap smear.

Beberapa pernyataan keluarga partisipan terkait spiritualitas pada partisipan survivor cancer yaitu:

"... ibu inshaaAllah shalat lima waktu mbak rutin, ... berdoa. Ibu ... berusaha sabar dan memang ibu terlihat berusaha kuat, dulu ibu bilang ikhlas menerima sakit ini mungkin semua teguran dari Allah atas dosa-dosa ibu yang telah lalu. ... ibu dzikir, mengucap istigfar disuarakan ketika tiduran ya sewaktu-waktu membacanyai." (T1, anak)

"...ibu menyampaikan sakit ini merupakan takdir jadi kami semua termasuk ibu harus ikhlas, harus sabar, harus pasrah... tetap harus ikhtiar maksimal dengan berobat dan berdoa. Ibu meminta kami didoakan agar panjang umur. Yang biasa kami lihat ya itu mbak ibu shalat berusaha tepat waktu, mushola yang didepan rumah diperbaiki dengan uang ibu ....ibu biasa ikut yasinan, dan biasanya bangun malam untuk shalat tahajut dan dzikir" (putra P3)

"...ibu tetap shalat lima waktu walau sakit, bisa jalan ke mushola depan rumah ini, mushola ini dibangun dulu pakai uang dan ditanah ibu ... ibu bilang kalau sudah pasrah tetapi harus tetap semangat sehat dan alhamdulillah betul ibu bisa sehat kembali, sering-sering mengucapkan istigfar dan dzikir agar lebih tenang dan kuat kata ibu kepada kami waktu itu..." (T4, anak)

" alhamdulillah istri saya tetap shalat lima waktu mbak, masih kuat dan bisa. Selain shalat wajib alhamdulillah ibu juga shalat tahajud,....yang saya sering dengar ibu biasa shalawatan, hehehe saya ikut ayem mendengarnya" (T5, suami).

Pada pengalaman spiritual survivor cancer cervix ini didukung oleh tiga belas coding yaitu:

1) Pasrah

Kepasrahan partisipan dalam penelitian ini dapat dilihat dari pernyataan berikut:

"Mungkin dengan sakit ini, merupakan cobaan atau teguran Allah sama hambaNya atas dosadosa yang pernah ibu lakukan, tidak ada manusia yang sempurna, pasti ada salah dan dosa, saya pasrah .... dengan semua ini...." (P1)

"... semua yang membuat hidup atau mati Allah seperti itu mbak yang awalnya saya takut akhirnya saya pasrah dengan apa ketetapan Allah, alhamdulillah sampai sekarang saya diberi sehat walafiat tidak ada halangan sehat selalu." (P2)

"Takdir dari Allah mbak, saya pasrah sakit seperti ini saya jalani dengan ikhlas saja, diterima apa yang Allah beri ...." (P3) 
"Biasa saja perasaan saya mbak, saya sudah pasrah, tidak sakit juga, tidak apa-apa dijalani saja" (P4)

"Saya lillahitaala saja, pasrah, saya tidak punya pikiran apa-apa. Hidup ya alhamdulillah mati ya alhamdulillah tidak papa" (P5)

2) Ikhlas

Keikhlasan partisipan dalam kanker yang diderita dapat dilihat dari pernyataan berikut ini:

"......saya ikhlas dengan semua ini, saya bersyukur mbak .... masih diberi kesempatan oleh Allah untuk beribadah. Saya berterimakasih mbak, sama anak-anak, yang telah merawat saya" (P1)

“... saya jalani dengan ikhlas saja, diterima apa yang diberi Allah. " (P3)

3) Bersyukur

Sikap syukur yang dijalani partisipan dapat dilihat dari pernyataan berikut ini:

"Alhamdulillah, sesudah kemoterapi pertama, perdarahan sudah berhenti mbak. Saya bersyukur, ada semangat hidup lagi, ada harapan lagi mbak hingga sekarang." (P1)

"... syukur alhamdulillah sampai sekarang saya diberi sehat walafiat ..." (P2)

4) Sabar

Sikap sabar yang dijalani partisipan dapat dilihat dari pernyataan berikut ini:

" semua itu harus ada niat mbak, sabar juga, inshaaAllah akan Allah beri jalan. Kalau saya ingat ketika sakit itu sedih mbak, bersyukur." (P1)

5) Istigfar

Partisipan dalam penelitian ini juga melakukan isigfar sebagai bentuk ibadah dan distraksi dapat dilihat dalam pernyataan berikut:

“ istigfar mbak, dzikir subhanallah alhamdulillah kepada Allah ....” (P1)

".... kalau sedang tidak merasakan sakit saya baca istigfar" (P4)

6) Dzikir

Dzikir yang biasa dilakukan oleh partisipan dalam penelitian ini sesuai dengan pernyataan berikut:

".....baca dzikir subhanallah, alhamdulillah, allahu akbar setiap ingat ..." (P1)

"Ya baca dzikir alhamdulillah subhanallah allahu akbar sebisanya ...." (P3)

"Ya baca hamdallah istigfar allahu akbar tidak terhitung, kalau ingat langsung dzikir " (P4)

7) Shalat lima waktu dengan khusyuk

Seluruh partisipan dalam penelitian melaksanakan shalat, pernyataan partisipan sebagai berikut:

"Ya mbak saya shalat lima waktu berusaha khusyuk dan tepat waktu " (P1) 
"... Shalat lima waktu lebih khusyuk." (P2)

"Yaitu, sholat wajib yang khusyuk....." (P3)

"Ya, kalau tidak lemah saya sholat lima waktu berusaha khusyuk...." (P4)

"Ya, sholat lima waktu berusaha tepat waktu" (P5)

8) Berdoa

Tiga dari lima partisipan menyampaikan berdoa sebagai bagian dari ikhtiar untuk meminta kesembuhan kepada Allah, dapat dilihat dari pernyataan berikut:

“.... Setiap ingat berdoa sama Allah, minta sama Allah, ya Allah beri kekuatan” (P1)

"... Memohon kepada Allah, ya Allah berikanlah saya kesehatan..." (P2)

"Dalam hati, saya berdoa, ya Allah saya dapat obat tidak?, kalau saya sehat saya minta panjang umur yang barokah..." (P3)

9) Shalat sunah

Tiga dari lima partisipan menyampaikan bahwa melaksanakan shalat tahajud, sesuai dengan pernyataan dibawah ini:

"Sholat duha, sholat tahajud, hajat, mutlak, ibadah yang lebih khusyuk" (P2)

"... Sholat sunnah sebisanya, sholat tahajud .... " (P3)

"Selain sholat ya mengaji, sholat tahajud, jumlah rokaatnya semampu ibu" (P5)

10) Takdir

Satu partisipan menyampaikan bahwa sakit ini merupakan takdir dari Allah, sesuai dengan yang disampaikan partisipan berikut:

"Takdir dari Allah mbak, saya pasrah, sakit seperti ini saya jalani dengan ikhlas ..." (P3)

11) Baca surah Yasin

Salah satu partisipan selalu membaca Yasin sebagai salah satu bentuk ibadah seperti dalam pernyataan berikut:

"... Anak-anak saya mintai tolong bacakan yasin ketika menunggui saya. Karena orang meninggal karena kanker serviks itu banyak, saya memang takut. Tetapi saya tidak ingin mati, saya ingin sehat" (P3)

12) Sedekah

Sebanyak dua partisipan menyampaikan sedekah merupakan sarana mendekatkan diri kepada Allah dalam meminta pertolongan-Nya, dapat dilihat dalam pernyataan berikut:

"Dulu sebelum sakit sudah membangun mushollah lalu rusak, waktu saya sakit saya minta tolong ke tukang untuk membetulkan sehingga mushollahnya bisa dipakai lagi, Alhamdullah" (P3)

"Betul mbak, saya sudah membangun mushollah dihalaman rumah saya dan menyampaikan ke anakanak, ponakan, dan warga untuk menggunakan mushollah tersebut untuk ibadah warga" (P4)

13) Baca sholawat 
Dua dari lima partisipan selalu membaca sholawat setiap waktu, dapat dilihat dari pernyataan berikut:

“... Sholawatan, agar tidak merasakan sakit" (P2)

"saya membaca sholawat sambil tiduran..." (P5)

\section{PEMBAHASAN}

Spiritualitas dan keimananberperan penting dalam menghadapi penyakit kanker. Beberapa survivorcancer memegang teguh nilai dan kepercayaan pada agama yang diyakininya (American Society of Clinical Oncology, 2015). Hal ini sesuai dengan hasil dalam penelitian ini.

Kebutuhan spiritual survivor cancer pada pasien kanker serviks merupakan kebutuhan yang sangat penting, kebutuhanakan rasa damai, kebutuhan menganut keyakinan agama dan kebutuhan memberi. Sedangkan bentuk kebutuhan spiritual yang paling diperlukan adalah berdoa. Pentingnya kebutuhan spiritual ini dapat dijadikan masukan untuk perawat dan rumah sakit untuk lebih memperhatikan kebutuhan spiritual pada wanita dengan kanker serviks dengan meningkatkan kompetensi dan fasilitas pemenuhan kebutuhan spiritual (Sudarmiati, 2013).

Berdasar hasil penelitian pada pasien kanker serviks diperoleh kesimpulan bahwa partisipan memiliki resiliensi yang baik, resiliensi merupakan kemampuan untuk dapat beradaptasi dan tetap teguh dalam situasi sulit. Partisipanberusaha agar dapat menjalani kehidupannya dengan baikdanyakin dapat sembuh. Faktor-faktor yang turut mendukung pembentukan resiliensi pada informan yaitu optimisme dankeyakinanakan kesembuhan, spiritualitas dan dukungan keluarga serta lingkungan sekitar (Shally, 2013).

Obat yang paling mujarab adalah ikhlas dan tawakal kepada Tuhan. Sebab, sikap ikhlas dan tawakal akan membuat penderita kanker serviks merasakan ketenangan akan penyakit yang diderita. ${ }^{(82)}$ Dalam studi al-Qur'an, syukur merupakan lawan dari kufur. Kufur dimaknai dengan menutup diri, sedangkan syukur diartikan mengakuiatau dirimembuka. Syukur termasuk bagian dari ajaran Islam tentang "terima kasih" yang penting dan sangat diperhatikan di hadapan Allah dan juga bagi manusia. Efek positif rasa syukur ditengarai dapatorang sedih menjadi bahagia (Mahfud, 2014).

Sebagian besar penderita penyakit kronis merasakan penderitaan yang hebat melebihi keadaan penyakit yang sesungguhnya.Pikiran negatif pada pasien dapat memperburuk kondisi fisik. Untuk mengurangi gejala kecemasan penderita harus memiliki keyakinan bahwa penyakitnya akan lebih baik bila penderita dapat bersikap sabar dalam menghadapi penyakitnya (Prayitno, 2015). Dalam mengatasi masalah psikologis yang muncul ialah dengan cara seperti mengingat keluarga, kegiatan spiritual salah satunya memperbanyak istigfar dan melakukan berbagai kegiatan sebagai distraksi (Wahyuni, 2015).

Kesembuhan penyakit tidak hanya dari segi lahir, seperti berobat, tetapi harus dibarengi dengan usaha batin, yaitu dengan memohon pertolongan kepada Allah SWT, salah satunya adalah dengan ibadah shalat. Allah berfirman dalam Al-Quran surat al-Baqarah ayat 153 yang artinya: "Hai orangorang yang beriman, jadikanlah sabar dan shalat sebagai penolongmu, sesungguhnya Allah beserta orang-orang yang sabar".

Islam memberikan keringanan pada umatnya untuk mengerjakan shalat sesuai dengan kondisi dan kemampuan. Apabila pasien penderita kanker tidak mampu melaksanakan shalat dengan berdiri, maka boleh dilakukan sambil duduk, berbaring, atau bahkan dengan isyarat yang bisa dilakukan pasien penderita kanker (Fitriyah, 2015). Doa dan amalan ibadah bagi pemeluk agama 
perlu dilakukan sesuai dengan agama dan keyakinannya. Doa dapat memberikan kesembuhan bagi mereka yang secara rutin mengamalkannya. Berbagai penelitian telah memberikan bukti bahwa berdoa, berdzikir dan amalan ibadah dapat menurunkan gejala-gejala depresi dan dapat memperbaiki kondisi fisik pasien (Prayitno, 2015).

Menurut hasil penelitian shalat sunah tahajud yang dilakukan dipenghujung malam dapat mendatangkan ketenangan. Sementara ketenangan itu sendiri terbukti mampu meningkatkan ketahanan tubuh imunologik dan meningkatkan usia harapan hidup. Sebaliknya, bentuk-bentuk dari tekanan psikologis seperti stress, depresi membuat seseorang rentan terhadap berbagai penyakit, infeksi dan mempercepat perkembangan pada sel kanker serta meningkatkan metastasis dalam (penyebaran sel kanker). Shalat sunah tahajud yang khusyuk dan ikhlas memberikan manfaat dari segi psikologis yang berupa perasaan tenang dan damai, dan dapat memberikan manfaat besar pada kesehatan jasmani sehingga berpengaruh kepada psikologi kesehatan individu (Chodijah, 2013).

"Tiada suatu bencana pun yang menimpa di bumi ini dan tidak pula pada diri kalian sendiri melainkan telah tertulis dalam kitab (Lauhul Mahfuz) sebelum kami menciptakannya." (Al-Hadid 22) Maka Hasan pun menjawab, "Baik, Demi Allah, Allah menetapkan suatu ketetapan di langit lalu Dia menentukan baginya ajal, bahwa ia akan terjadi pada hari ini, jam sekian, begini dan begitu, pada yang khusus dan yang umum (Jauziyah, 2000). Dalam QS. Al-Munafiqun:10 Dan belanjakanlah sebagian dari apa yang telah kami berikan kepadamu sebelum datang kematian kepada salah seorang di antara kamu; lalu ia berkata; "Ya Rabb-ku, mengapa Engkau tidak menagguhkan (kematian)ku sampai waktu yang dekat, yang menyebabkan Aku dapat bersedekah dan aku termasuk orang-orang yang shaleh?". " Dan barang apa saja yang kamu nafkahkan, maka Allah akan menggantinya dan Dia-lah pemberi rezeki yang sebaik-baiknya". (QS. Saba:39) (AsySyaqawy, 2009). Dalam Al-Quran surah al-Ahzab:56 "Sesungguhnya Allah dan malaikat-malaikatNya bershalawat untuk Nabi. Hai orang-orang yang beriman, bershalawatlah kamu untuk Nabi dan ucapkanlah salam penghormatan kepadanya" (Amin, 2013).

Pada penelitian ini terdapat beberapa keterbatasan yaitu peneliti belum mengkaji secara mendalam tingkat kekhusyukan partisipan dalam menjalankan kegiatan spiritual. Implikasibagikeperawatanadalahdalam memberikan asuhan keperawatan spiritual kepada pasien kanker secara komprehensif dan holistik, perawat dianjurkan membimbing pasien dalam melaksanakan kegiatan spiritual dengan harapan pasien dapat survive dan memiliki kualitas hidup yang lebih baik, dan apabila pasien meninggal dapat meninggal dengan keadaan khusnul khotimah.

\section{SIMPULAN DAN SARAN}

Simpulan

Hasil penelitian ini menunjukkan bahwa kelima survivor cervical cancer menerapkan kegiatanspiritual yang positif dalam menghadapi kanker serviks hingga dinyatakan sembuh, dengan cara: pasrah, ikhlas, bersyukur, sabar, istigfar, dzikir, shalat lima waktu dengan khusyuk, berdoa, shalat sunah, takdir, baca surah yasin,sedekah, dan membaca sholawat.

Saran

Perlu adanya penelitian lanjutan mengenai study empirik menggunakan desain kuantitatif. 


\section{KEPUSTAKAAN}

Achmadi, \& Askandar, T. B. S. Karakteristik Penderita Kanker Serviks 2006-2010 di RSUD dr. Soetomo. Majalah Obstetri \& Gynekologi, Vol 19 No.3 September-Desember 2011:128-133, 18, 128-133.(2011).

Afiyanti, Y.,\& Rachmawati N.Metodologi Penelitian Kualitatif Dalam Riset Keperawatan. Edisi 1. Jakarta: Rajawali Pers.(2014).

American Cancer Society. The History of Cancer. ACS-American Cancer Society. (2014). 1-16. from: https://doi.org/10.1038/nrc1279

American Society of Clinical Oncology. Cancer Survivorship Next Step for Patient and Their Families. Conquer Cancer Foudation.(2015).

Amin S. Shalawat Kepada Nabi, Keutamaan Serta Faidahnya. 2013.

Asy-Syaqawy AA. Keutamaan Bershedekah. 2009.

Badan Penelitian Dan Pengembangan. Riset Kesehatan Dasar. Badan Penelitian Dan Pengembangan Kesehatan Kementrian Kesehatan RI. (2013).

Canbaz S, Sunter AT, Dabak S, Peksen Y. The prevalence of chronic disease and quality of live in eldery people in Samsun. Turk J Med Sci 2002; 33: 335-40.

Chamberlain, J.Cancer Survivors 'Stories They did it . You can too! Long Island Press. (2011).

Chodijah S. Konsep Shalat Tahajud Melalui Pendekatan Psikoterapi Hubungannya Dengan Psikologi Kesehatan (Penelitian Di Klinik Terapi Tahajud Surabaya). 2013.

Elo, S., \& Kyngäs, H. The qualitative content analysis process. Journal of Advanced Nursing.(2008).62(1), 107-115. from: https://doi.org/10.1111/j.1365-2648.2007.04569.x

Fitriyah Q. Implementasi Model Bimbingan Rohani Islam Penderita Kanker Di Rumah Sakit Islam Sultan Agung. 2015.

Gayatri, D., \& Nurachmah, E. Peluang Ketahanan Hidup 5 Tahun Pasien Kanker Serviks Di RSUPN Dr Cipto Mangunkusumo \& RSK Dharmais, Jakarta, 2002. Jurnall Keperawatan Indonesia.(2003). 7, 17-21.

Hasanah, S. N., \& Widowati, L. Jamu Pada Pasien Tumor/Kanker sebagai Terapi Komplementer Herbal as A Compelementary Therapy for Tumor/Cancer Patients Indonesia. (2016).6(1):4959.

Hodges, K., \& Winstanley, S. Effects of optimism, social support, fighting spirit, cancer worry and internal health locus of control on positive affect in cancer survivors: A path analysis. Stress and Health.(2012). 28(5), 408-415. from: https://doi.org/10.1002/smi.2471

Indriatmo, W., Murhayati, A., \& Setiyajati, A. Hubungan Antara Dukungan Keluarga Dengan Motivasi Untuk Sembuh Pada Pasien Kanker Yang Menjalani Kemoterapi Di Ruang One Day Care RSUP Dr Moewardi. (2016). 
Jauziyah IQ Al. Qadha dan Qadar.pdf.crdownload. Jakarta: Pustaka Azzam; 2000.

Mukwato, K. P., Mwape, L., Maimbolwa, C. M., Muleya, C. M., \& Namushi, L. B. Stress and coping with cervical cancer by patients: A qualitative inquiry. International Journal of Psychology and Counselling. (2015). 7(6), 94-105. from: https://doi.org/10.5897/IJPC2015.0313

Kecheng, X. FUDA Indonesia • Menjadi konsultan kanker. (2016).

Mahfud C. The Power Syukur Tafsir Kontekstual Konsep Syukur dalam al-Qur' an. 2014;9.

Natuveli G, Wiggins R, Hildon Z, Blane D. Functional limitation in long standing illness and quality of life: evidence from a national survey. BMJ Z(2005z). 331: 1382-3.

Nidich, S. I., Fields, J. Z., Rainforth, M. V, Pomerantz, R., Cella, D., Kristeller, J. Schneider, R. H. A Randomized Controlled Trial of the Effects of Transcendental Meditation on Quality of Life in Older Breast Cancer Patients, (August 2003). (2009). from: https://doi.org/10.1177/1534735409343000

Nuraeni, N. Persepsi Dan Harapan Perempuan Dengan Kanker Serviks Terhadap Asuhan Keperawatan Spiritual Di RSUPDr Hasan Sadikin Bandung. (2010).

Penelitian, B., \& Pengembangan, D. A. N. Riset Kesehatan Dasar. (2013).

Peppercorn, J. M., Smith, T. J., Helft, P. R., Debono, D. J., Berry, S. R., Wollins, D. S., Schnipper, L. E. American Society of Clinical Oncology Statement: Toward Individualized Care for Patients With Advanced Cancer,29(6). (2011). from: https://doi.org/10.1200/JCO.2010.33.1744

Polit, D.F., \& Hungler, B. Nursing: generating and assessing vidence for nursing practice. Eight edition. (2012).

Potter, P.A., \&Perry, A. Buku Ajar Fundamentals Keperawatan Konsep Proses Dan Praktik. Jakarta: EGC. (2005).

Pusat Data dan Informasi. Buletin Jendela Data dan Informasi Kesehatan (Situasi Penyakit Kanker). (2015).Bakti Husada, ISSN 2088-270X.

Semarang, D. K. K. Angka Kejadian Penyakit Tidak Menular. (2015).

Shally RDV. Resiliensi Pada Penderita Kanker Serviks Stadium Lanjut. Universias Muhammadiyah Surakarta; 2013.

Subagja, I. Kanker Serviks Pembunuh Nomor 1 Perempuan Indonesia. (2017). Retrieved from https://kumparan.com/indra-subagja/kanker-serviks-pembunuh-nomor-1-perempuanindonesia.

Sudarmiati S, Fithriana NL. SPIRITUALITAS WANITA DENGAN KANKER SERVIK. 2013;168-71.

Sweezey, N. Cancer The Problem ( 1 ).(2014).

Threfina, E. Cerita Perjuangan Evie Trefina, Penyintas Kanker Serviks. CNN Indonesia. (2017). 
Wahyuni, Dwi; Huda NUGT. Studi Fenomenologi: Pengalaman Pasien Kanker Stadium Lanjut Yang Menjalani Kemoterapi. 2015;2(2).

WHO. Word Cancer Report 2014. (2015). 